\title{
Mechanical and Thermal Properties of Pumice Powder Filled PPS Composites
}

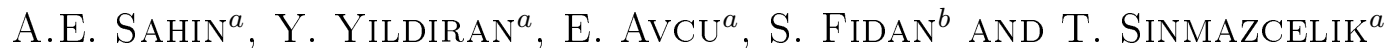 \\ ${ }^{a}$ Kocaeli University, Mechanical Engineering Dept., Umuttepe Campus, 41380 Izmit, Turkey \\ ${ }^{b}$ Kocaeli University, School of Civil Aviation, Arslanbey Campus, 41285 Izmit, Turkey
}

\begin{abstract}
Recently, it is common application to use particle materials as fillers to improve engineering properties and lower the cost of finished product. Pumice powder is cheaper than most of traditional particle fillers, however use of pumice powders as a reinforcing material in composites has not been studied in literature. Hence, in this study we have investigated the mechanical and the thermal properties of pumice powder filled polyphenylenesulphide (PPS) composites. PPS composites were reinforced with pumice powder at different loading rates $(0,1,3.5$, and $10 \mathrm{wt} \%)$ and they were manufactured by twin screw extruder and injection molding machine. Thermal properties were investigated by thermogravimetric analysis and differential scanning calorimeter methods. Moreover, mechanical properties such as barcol hardness, tensile strength, and modulus of samples were investigated. Thermal properties of composite samples have varied significantly depending on the loading rate. Also mechanical properties of pumice powder filled PPS composites have showed better results than pure PPS. According to test results both of mechanical and thermal properties of composites have improved with pumice powder reinforcement and it is determined that pumice powders can be used instead of traditional particle fillers.
\end{abstract}

DOI: 10.12693/APhysPolA.125.518

PACS: 81.05.Qk, 81.70.Bt, 81.70.Pg

\section{Introduction}

Thermoplastic composites are increasingly found place in automotive industry, aeronautics and space applications, owing to their great toughness, impact resistance, high specific stiffness and strength. Moreover, thermoplastics are more economic compared to thermosets [1-4].

Polyphenylene sulphide (PPS) is a semicrystalline thermoplastic, hence it has dimensional stability and balanced flow properties and it also has high temperature, chemicals and liquids resistance. It is preferred at different industrial applications because it can work at high temperature. Furthermore, it has really high dimensional stability and it is an easily processable polymer. Moreover it has elegant mechanical properties. On the other hand, it has brittle structure and very high cost. In order to maintain these disadvantages fibre or/and particle filled composites are widely produced [5-7].

Pumice is volcanic based alumina silica which is mainly composed of $\mathrm{SiO}_{2}$. Pumice has porous structure and its porous structure is formed by dissolved gases precipitated during the cooling as the lava hurtles through air. Due to its porous structure it has low density and high thermal insulation. It also has high temperature resistance and chemical resistance, for these reasons it increasingly became preferable material at industrial applications [8-11].

In this study pumice reinforced PPS matrix composites are produced with various reinforcement concentrate. Filling pumice particles reduces the cost. However, we should know effect of the pumice filling on the mechanical and thermal properties of PPS. Therefore, mechanical properties of the pumice filled PPS composites are investigated by tensile tests and barcol hardness tests, thermal properties of the composites are investigated by thermogravimetric analysis (TGA) and differential scanning calorimeter (DSC) methods. It is aimed to understand the effects of the pumice concentration on the mechanical and the thermal properties of the PPS composites.

\section{Experimental}

\subsection{Materials}

Granule structure polyphenylene sulphide Fortron $^{\circledR}$ PPS 1200L1 polymer is used as a matrix material which has been supplied from Ticona Company, Sulzbach, Germany. Pumice powders are used as a filling material and they are supplied from Karakaya Pumice Company, Manisa, Turkey.

\subsection{Preparation of composites}

Various dimensional pumice powders (80 mesh and 180 mesh) are filled in PPS polymer with various weight ratios using twin-screw extruder which is produced by DSM XPLORE Company. They are mixed at $340^{\circ} \mathrm{C}$ and $100 \mathrm{rpm}$ rotational speed at extruder. The extruded samples were injected with $340{ }^{\circ} \mathrm{C}$ at $80^{\circ} \mathrm{C}$ mould temperature.

\subsection{Methods}

Tensile properties were measured on Shimadzu AG-X Universal Tester with $1 \mathrm{~mm} / \mathrm{min}$ tensile speed at room temperature.

Hardness tests were measured on Zwick Barcol Tester. All samples were measured at least fifteen times from different points against to standard deviation.

TGA is investigated with TA Instruments TGA Q50. Test samples are prepared around $10 \mathrm{mg}$ and the prepared samples are heated from room temperature to $1000^{\circ} \mathrm{C}$ with $20^{\circ} \mathrm{C} / \mathrm{min}$ heating rate.

DSC is measured on TA Instruments Q-Series Q200. Test samples are prepared with a mass of about $10 \mathrm{mg}$ and prepared samples are heated at room temperature 
to $340^{\circ} \mathrm{C}$ with $10^{\circ} \mathrm{C} / \mathrm{min}$ heating rate. From these tests we obtained glass transition temperature $\left(T_{\mathrm{g}}\right)$, melting temperature $\left(T_{\mathrm{m}}\right)$, and crystallinity of PPS and its composites.

\section{Result and discussion}

\subsection{Tensile properties}

Tensile strength of pumice powder filled PPS composites at various loading rates is shown in Fig. 1a. On investigating Fig. 1a tensile strengths are increased with pumice fillers for all the filling rates compared to pure PPS. However maximum tensile strength reached at $5 \mathrm{wt} \%$ pumice filled composites. $10 \mathrm{wt} \%$ filled samples have worse tensile strength than $5 \mathrm{wt} \%$ filled samples but also better than pure PPS.

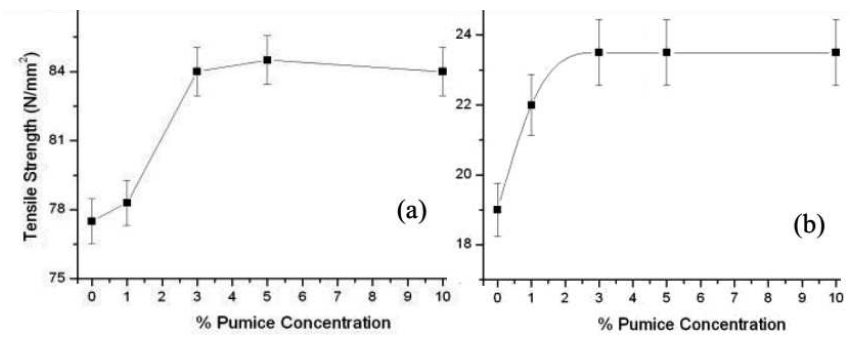

Fig. 1. Effect of pumice powder concentration on (a) tensile strength and $(\mathrm{b})$ tensile modules.

Tensile modules are shown in Fig. 1b, pumice fillers increased the tensile modules for each filler rates. Pumice fillers increased tensile modules up to $3 \mathrm{wt} \%$ rate, above $3 \mathrm{wt} \%$ pumice rate did not affect the tensile modules.

\subsection{Hardness property}

Barcol hardness test results of samples are shown in Fig. 2. Increasing with particle rate in composite, the hardness of samples is increased. Pure PPS has nearly 18 barcol hardness while $10 \mathrm{wt} \%$ pumice filled PPS has nearly 24 barcol hardness.

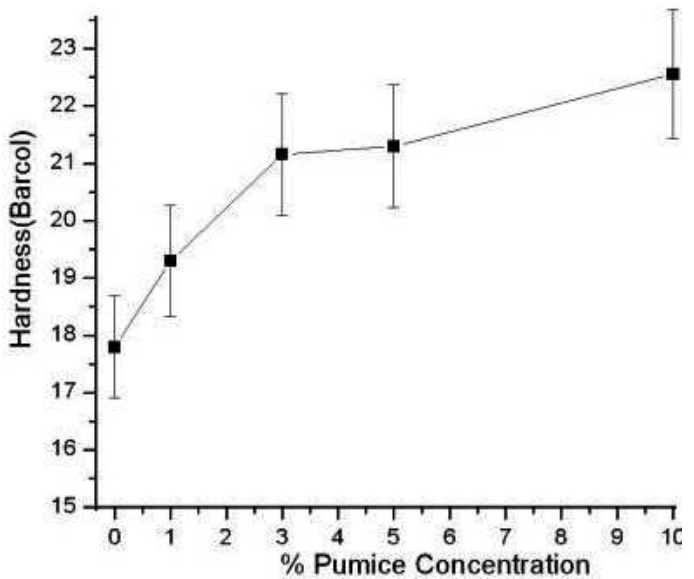

Fig. 2. Effect of pumice powder concentration on hardness of PPS.

\subsection{Thermogravimetric analysis}

During TGA test samples are heated from room temperature to $1000^{\circ} \mathrm{C}$. Degradation of samples is investigated with calculated weight loss. $T_{10}, T_{20}(10 \%$ and $20 \%$ weight loss temperatures) and maximum degradation temperatures of samples are given in Fig. 3 . In Fig. 3, pumice fillers have no considerable effect on $T_{10}$ and $T_{20}$ temperatures, however, maximum degradation temperature is increased with pumice powder adding.

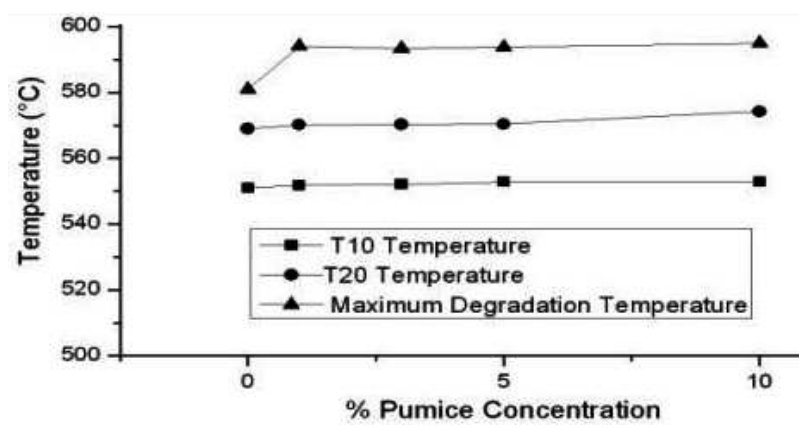

Fig. 3. Effect of pumice powder concentration on $T_{10}$, $T_{20}$ and maximum degradation temperature of PPS.

\subsection{Differential scanning calorimetry}

Glass transition temperature $\left(T_{\mathrm{g}}\right)$, melting temperature $\left(T_{\mathrm{m}}\right)$, and crystallinity values are obtained from DSC. According to Fig. 4a glass transition temperature increased with increase of pumice powder rate. While $T_{\mathrm{g}}$ of pure PPS is $113.30^{\circ} \mathrm{C}, T_{\mathrm{g}} 10 \mathrm{wt} \%$ pumice powder filled PPS is $118.83^{\circ} \mathrm{C}$. Adding pumice powder into the PPS matrix has not important influence on melting temperature of PPS by Fig. 4b. Crystallinity rate of samples are calculated from melting enthalpy with the aid of DSC. According to Fig. 4c whereas adding $1 \%$ pumice powder increased the crystallinity of PPS, adding above $1 \%$ pumice powder decreased the crystallinity of PPS.
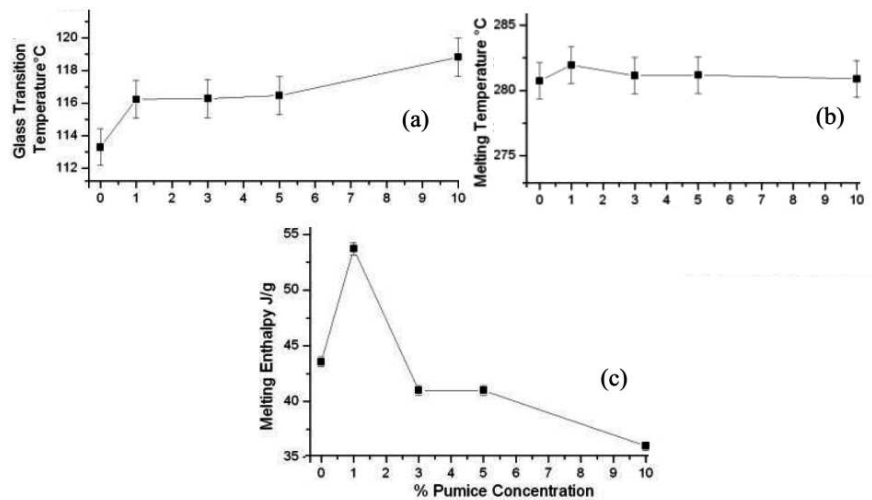

Fig. 4. Effect of pumice powder concentration on (a) $T_{\mathrm{g}}$, (b) $T_{\mathrm{m}}$, and (c) melting enthalpy of PPS. 


\section{Conclusion}

1. Adding pumice powder into the PPS matrix increased the tensile strength value of PPS and maximum tensile strength value is seen at $5 \%$ pumice powder concentrate. Tensile module of PPS is also increased with adding pumice powder. Maximum tensile module was reached at $3 \%$ pumice powder concentration. Moreover, above $3 \%$ pumice concentrate tensile modules are unchanged.

2. Barcol hardness test showed that increase of pumice concentration in PPS increased the hardness of PPS.

3. TGA showed that adding pumice powder in PPS matrix has no significant effect on $T_{10}$ and $T_{20}$ temperatures of PPS. On the other hand, maximum degradation temperature is increased with adding pumice powder.

4. DSC test results show that $T_{\mathrm{g}}$ values are increased with increase of pumice powder concentration. $T_{\mathrm{m}}$ values are not affected by pumice powder adding. Furthermore, adding $1 \%$ concentration pumice powder increased melting enthalpy, however adding above $1 \mathrm{wt} \%$ rate decreased the melting enthalpy.

\section{References}

[1] P.P. Parlevliet, H.E.N. Bersee, A. Beukers, Composites Part A 37, 1847 (2006).

[2] G. Sala, D. Cutolob, Composites Part A 28A, 637 (1997).

[3] O. Sayman, H. Çallioğlu, Composite Struct. 50, 199 (2000).

[4] H. Ning, U. Vaidya, G.M. Janowski, G. Husman, Composite Struct. 80, 105 (2006).

[5] C.J. Schwartz, S. Bahadur, Wear 251, 1532 (2001).

[6] Z. Chen, T. Li, Y. Yang, X. Liu, R. Lv, Wear 257, 696 (2004).

[7] T. Hu, J. Juuti, H. Jantunen, J. Europ. Ceram. Soc. 27, 2923 (2007).

[8] M. Kitis, S.S. Kaplan, Chemosphere 68, 1846 (2007).

[9] B. Ersoy, A. Sariisik, S. Dikmen, G. Sariisik, Powder Technology 197, 129 (2010).

[10] B. Felekoglu, Construct. Build. Mater. 28, 305 (2012).

[11] V. Nozahic, S. Amziane, G. Torrent, K. Saïdi, H.D. Baynast, Cement Concrete Composites 34, 231 (2012). 